POLSKI INSTYTUT STUDIÓW NAD SZTUKA Ś ŚWIATA

INSTITUTO POLACO DE INVESTIGACIÓN DEL ARTE MUNDIAL

\title{
SZTUKA
}

\section{AMERYKI ŁACIŃSKIEJ}

\section{ARTE}

\section{DE AMÉRICA LATINA}

ODZYSKIWANIE MARGINALIZOWANYCH NARRACII I PERSPEKTYWY DEKOLONIALNE W SZTUCE I TEATRZE W ARGENTYNIE OD POCZĄTKU XX DO XXI WIEKU

RECUPERACIÓN DE RELATOS MARGINALIZADOS $Y$ PERSPECTIVAS DECOLONIALES EN EL ARTE $Y$ TEATRO EN ARGENTINA DESDE PRINCIPIOS

DEL SIGLO XX HASTA LA ACTUALIDAD

2018, NR 8 


\section{SZTUKA AMERYKI ŁACIŃSKIEJ / ARTE DE AMÉRICA LATINA}

Rada Naukowa:

Członkowie polscy:

Jerzy Malinowski (przewodniczący) (Uniwersytet Mikołaja Kopernika w Toruniu), Zbigniew Bania (Uniwersytet Kardynała Stefana Wyszyńskiego), Magdalena Śniadecka-Kotarska (Uniwersytet Łódzki, Uniwersytet Warszawski), Joanna Pietraszczyk-Sękowska (Uniwersytet Łódzki)

Członkowie zagraniczni:

María Cristina Valerdi Nochebuena (Benemérita Universidad Autónoma de Puebla, México), André Tavares (Universidade Federal de São Paulo, Brasil), Yobenj Aucardo Chicangana Bayona (Universidad Nacional de Colombia, sede Medellín), Doris Bieńko de Peralta (Escuela Nacional de Antropología e Historia, Instituto Nacional de Antropología e Historia, México), Olga Isabel Acosta Luna (Museo de Arte Colonial, Bogotá, Colombia), Guadalupe Romero Sánchez (Universidad de Granada, Espańa)

Redaktor naczelny: dr Ewa Kubiak Sekretarz: dr Katarzyna Szoblik

Recenzenci: prof. dr hab. Jan Wiktor Sienkiewicz prof. dr hab. Aneta Pawłowska

Redaktorka tomu: dr Katarzyna Cytlak

Redaktor statystyczny: dr. inż. Błażej Ciarkowski

Redaktorzy tematyczni:

- sztuka nowoczesna i współczesna: dr Łukasz M. Sadowski

- sztuka kolonialna: dr Agata Andrzejewska

- sztuka tradycyjna i ludowa: dr Magdalena Nierzwicka, dr Joanna Pietraszczyk-Sękowska

- sztuki audiowizualne: dr Anna Wendorff

Redaktorzy językowi:

- j. polski: dr Krzysztof Cichoń

- j. hiszpański: mgr Daria Ornat, dr Anna Wendorff

- j. angielski: mgr Karolina Grzech, mgr Zofia Majda

Redaktor prowadzący: Paweł Jaroniak

Redaktor techniczny: Tomasz Czapski

Korekta: Zespół

Projekt okładki: Krzysztof Galus

Adres Redakcji:

Polski Instytut Studiów nad Sztuką Świata

ul. Warecka 4/6-10, 00-040 Warszawa

www.world-art.pl; biuro@world-art.pl

(C) Copyright by Wydawnictwo Adam Marszałek

(C) Copyright by Polski Instytut Studiów nad Sztuką Świata

Toruń 2018

ISSN 2299-260X

Wydawnictwo prowadzi sprzedaż wysyłkową: tel./fax 5664850 70, e-mail: marketing@marszalek.com.pl

Wydawnictwo Adam Marszałek, ul. Lubicka 44, 87-100 Toruń tel. 5666422 35, 5666081 60, e-mail: info@marszalek.com.pl, www.marszalek.com.pl Drukarnia nr 2, ul. Warszawska 54, 87-148 Łysomice, tel. 566783478 


\section{Contenido}

\section{Prefacio, Katarzyna Cytlak}

Recuperación de relatos marginalizados y perspectivas decoloniales en el arte y teatro en Argentina desde principios del siglo XX hasta la actualidad

Foreword, Katarzyna Cytlak

The Recuperation of Marginalized Plots and Decolonial Perspectives of Art and Theatre in Argentina from the Beginning of the $20^{\text {th }}$ to $21^{\text {st }}$ Centuries

\section{Przedmowa, Katarzyna Cytlak}

Odzyskiwanie marginalizowanych narracji i perspektywy dekolonialne w sztuce i teatrze w Argentynie od początku XX do XXI wieku

\section{I.}

\section{Rituales de muerte - Performance - Actuar desde el estar}

\section{Juan Ignacio Vallejos}

Fabián Gandini y la est(ética) de la fisura

\section{Juan Pablo Pérez}

Ritualizar la muerte. Identidades latinoamericanas en las prácticas conceptuales de Alfredo Portillos

\section{Malena La Rocca}

Entre rituales fúnebres y movilizaciones de protesta.

Modos de hacer arte y política durante la última dictadura cívico-militar argentina

\section{María Laura (Malala) González}

Teatro y posdictadura: La Organización Negra y sus modos de intervenir el espacio público en clave performática 


\section{II.}

RE-VISIONES DE RELATOS MARGINALIZADOS

De la historia del arte en Argentina

Georgina G. Gluzman

Las bañistas de Raquel Forner: mujeres modernas

Isabel Plante

Crítica institucional desde del 'Tercer Mundo'.

Cultura: dentro y fuera del museo

Andrea Díaz Mattei

"Los argentinos descendemos de los barcos", pero... ¿¿de cuáles?

Apuntes sobre la (in)visibilización de la negritud rioplatense

en las prácticas artísticas contemporáneas.... 


\section{Contents}

\section{Prefacio, Katarzyna Cytlak}

Recuperación de relatos marginalizados y perspectivas decoloniales en el arte y teatro en Argentina desde principios del siglo XX hasta

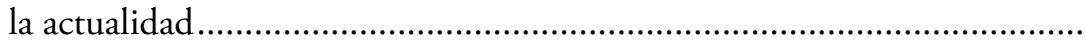

Foreword, Katarzyna Cytlak

The Recuperation of Marginalized Plots and Decolonial Perspectives of Art and Theatre in Argentina from the Beginning of the $20^{\text {th }}$ to $21^{\text {st }}$ Centuries

\section{Przedmowa, Katarzyna Cytlak}

Odzyskiwanie marginalizowanych narracji i perspektywy dekolonialne w sztuce i teatrze w Argentynie od początku XX do XXI wieku

I.

Rituals of Death - Performance - Acting from the being (IN THE WORLD)

\section{Juan Ignacio Vallejos}

Fabian Gandini and the est(ethics) of the fissure

\section{Juan Pablo Pérez}

To ritualize death. Latin American identities in the conceptual practices of Alfredo Portillos

\section{Malena La Rocca}

Between funeral rituals and protest mobilizations.

Methods of engaging in art and politics during the last civilian-military Argentinian dictatorship

\section{María Laura (Malala) González}

Theater and post-dictatorship: La Organización Negra (The Black

Organization) and its ways of intervening in public space (performative key) 


\section{II. \\ RE-VISIONS OF MARGINALIZED PLOTS \\ IN THE HISTORY OF ART IN ARgentina}

Georgina G. Gluzman

Las bañistas of Raquel Forner: Modern Women

Isabel Plante

Institutional criticism from the 'Third World'.

Cultura: dentro y fuera del museo

Andrea Díaz Mattei

"Argentinians descend from ships", but... from which ones?

Notes on the (in)visibilisation of River Plate negritude

in the contemporary artistic practices 


\section{Spis treści}

\section{Prefacio, Katarzyna Cytlak}

Recuperación de relatos marginalizados y perspectivas decoloniales en el arte y teatro en Argentina desde principios del siglo XX hasta

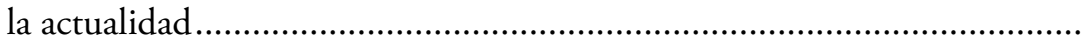

\section{Foreword, Katarzyna Cytlak}

The Recuperation of Marginalized Plots and Decolonial Perspectives of Art and Theatre in Argentina from the Beginning of the $20^{\text {th }}$ to $21^{\text {st }}$

Centuries

\section{Przedmowa, Katarzyna Cytlak}

Odzyskiwanie marginalizowanych narracji i perspektywy dekolonialne w sztuce i teatrze w Argentynie od początku XX do XXI wieku

I.

Rytuaty śmierci - Performance - Dziąania z POZycji bycia (W ŚWIECIE)

\section{Juan Ignacio Vallejos}

Fabian Gandini i est(etyka) pęknięcia

\section{Juan Pablo Pérez}

Rytualizacja śmierci. Tożsamości Ameryki Łacińskiej w konceptualnych praktykach Alfredo Portillosa

\section{Malena La Rocca}

Między rytuałami pogrzebowymi a mobilizacjami protestacyjnymi.

Sposoby uprawiania sztuki i polityki w okresie ostatniej

cywilno-wojskowej dyktatury argentyńskiej

\section{María Laura (Malala) González}

Teatr i postdyktatura: Organización Negra i jej sposoby interweniowania w przestrzeni publicznej (klucz performatywny) 


\section{II.}

RE-WIZJE MARGINALIZOWANYCH WĄTKÓW

W HistoriI SZTUKi w Argentynie

Georgina G. Gluzman

Las bañistas autorstwa Raquel Forner: współczesne kobiety

Isabel Plante

Instytucjonalna krytyka z „krajów Trzeciego Świata”:

Cultura: dentro y fuera del museo

Andrea Díaz Mattei

„Argentyńczycy pochodza ze statków”, ale... z których?

Uwagi na temat (nie)widoczności „négritude” regionu rzeki La Platy we współczesnych działaniach artystycznych 